\title{
Remuneração de Executivos e Desempenho Financeiro: um Estudo com Empresas Brasileiras
}

\section{Resumo}

O objetivo desta pesquisa foi investigar a relação entre a remuneração dos executivos e o desempenho financeiro nas empresas brasileiras. Os dados da pesquisa são secundários e foram coletados de dois bancos de dados: a) Programa de Estudos em Gestão de Pessoas (PROGEP); b) Fundação Instituto de Pesquisas Contábeis, Atuariais e Financeiras (FIPECAFI). A amostra não probabilística é formada por 82 empresas não financeiras. Para operacionalizar a variável independente "remuneração", foram utilizados, além do salário mensal médio e do salário variável médio, três índices que foram criados especialmente para esta pesquisa: benefícios, carreira e desenvolvimento. Esses índices mediram o acesso a benefícios; a mecanismos de estímulo e suporte à carreira; a mecanismos de estímulo à educação. Trata-se de itens oferecidos pelas empresas a seus diretores, vice-presidentes e presidentes, os quais são denominados, neste trabalho, de "executivos". Esses dados de remuneração são do exercício de 2008. Quanto à variável dependente "desempenho financeiro", foram utilizados três indicadores contábeis: crescimento das vendas, retorno sobre patrimônio líquido e retorno sobre ativos, dos exercícios sociais de 2008 e de 2009 . O porte das empresas e o setor de atuação foram utilizados como variáveis de controle. Os resultados do teste de correlação de Spearman apontaram a existência de relação significante entre remuneração financeira e desempenho financeiro. $\mathrm{E}$ os resultados da análise de regressão linear múltipla mostraram a existência de relação significante entre remuneração financeira e desempenho financeiro e entre remuneração não financeira e desempenho financeiro.

Palavras-chave: executivos; remuneração financeira; remuneração não financeira; desempenho financeiro; Brasil.

\section{Elizabeth Krauter}

Doutora em Administração (USP), Professora da Universidade de São Paulo (FEA-RP/USP). Contato: Av. Bandeirantes, 3900, sala 23 Bloco B2, Monte Alegre, Ribeirão Preto, São Paulo, CEP: 14040-905. E-mail: ekrauter@usp.br

A autora agradece o Programa de Estudos em Gestão de Pessoas (PROGEP) e a Fundação Instituto de Pesquisas Contábeis, Atuariais e Financeiras (FIPECAFI) por terem disponibilizado os dados para a realização da pesquisa e o Conselho Nacional de Desenvolvimento Científico e Tecnológico (CNPq) por ter financiado o projeto de pesquisa. 


\section{Introdução}

A remuneração dos executivos é um assunto que tem atraído a atenção da mídia. Os escândalos da Enron e da WorldCom em 2001 e a crise do subprime em 2007 tiveram grande repercussão nos principais meios de comunicação de todo o mundo e revelaram falhas na estrutura de governança corporativa das empresas. A remuneração é um dos mecanismos de governança, utilizada para alinhar os interesses de acionistas e executivos.

Várias pesquisas têm sido realizadas para investigar se existe uma relação entre a remuneração dos executivos e o desempenho das empresas. Elas foram desenvolvidas, principalmente, nos Estados Unidos (Kato, Kim \& Lee, 2005), em que as informações sobre a remuneração dos executivos estão disponíveis. Os resultados dessas pesquisas são divergentes e não conclusivos. Algumas dessas pesquisas encontraram relações fracas; outras observaram relações não significantes entre as variáveis (Bálkin \& Gómez-Mejia, 1987; Barkema \& Gómez-Mejia, 1998).

A abordagem mais utilizada nessas pesquisas foi a teoria da agência. Segundo ela, o principal (acionista) contrata um agente (executivo) para executar alguma tarefa em seu favor, envolvendo a delegação de autoridade para tomada de decisão. Se as partes - acionista e executivo - agirem de modo a maximizar sua utilidade pessoal, existem razões para acreditar que o agente nem sempre agirá de acordo com os melhores interesses do acionista (Jensen \& Meckling, 1976).

A realização de estudos em outros contextos, diferentes do norte-americano, pode contribuir para o melhor entendimento deste tema (Barkema \& Gómez-Mejia, 1998; Kato et al., 2005). No Brasil, devido à resistência das empresas em divulgar os dados de remuneração, as pesquisas sobre a relação entre a remuneração dos executivos e o desempenho financeiro são ainda escassas (Larrate, 2013).

A importância e a relevância do tema, as divergências encontradas nos resultados das pesquisas anteriores realizadas em outros países, o interesse em investigar a existência de relação entre a remuneração dos executivos e o desempenho financeiro nas empresas brasileiras motivaram a realização desta pesquisa. Ela se diferencia das pesquisas anteriores ao utilizar conceitos mais amplos para operacionalizar as variáveis. Com relação à variável independente "remuneração", essa pesquisa considerou a remuneração financeira e a remuneração não financeira. A remuneração financeira incluiu a remuneração direta (salário mensal + salário variável) e a remuneração indireta (benefícios) recebida pelos executivos. A remuneração financeira englobou aspectos relacionados à carreira, à educação e ao desenvolvimento pessoal e profissional dos executivos. As pesquisas anteriores utilizaram apenas a remuneração direta.

Com relação à variável dependente desempenho financeiro, as pesquisas anteriores utilizaram apenas um indicador contábil de um exercício social. Ela utiliza três indicadores contábeis - crescimento das vendas, retorno sobre patrimônio líquido (ROE) e retorno sobre ativos (ROA) de dois exercícios sociais - 2008 e 2009. Com exceção das pesquisas realizadas por $\operatorname{Krauter}(2009,2012)$, não existem outras, nacionais ou internacionais, sobre o tema, que tenham utilizado tal abordagem.

O presente trabalho teve como objetivo: Investigar a relação entre a remuneração dos executivos e o desempenho financeiro nas empresas brasileiras. Adicionalmente, procurou conhecer as características do sistema de remuneração dos executivos das empresas brasileiras. A pesquisa procurou responder à seguinte pergunta: Qual a relação entre a remuneração dos executivos e o desempenho financeiro nas empresas brasileiras?

\section{Remuneração e Desempenho Financeiro}

A remuneração é um dos sistemas mais importantes e complexos da administração de Recursos Humanos. Ao mesmo tempo em que estimula a busca por desempenhos cada vez melhores, o sistema de remuneração alinha o comportamento das pessoas com os objetivos estratégicos do negócio, levando a empresa a alcançar níveis superiores de desempenho financeiro (Bálkin \& Gómez-Mejia, 1987; Gómez-Mejia \& Welbourne, 1988). A Figura 1 apresenta o conceito de remuneração utilizado neste trabalho. 
A remuneração financeira "é a contrapartida econômica e/ou financeira de um trabalho realizado pela pessoa" (Hipólito \& Dutra, 2012, pp.1-2). Pode ser dividida em remuneração direta e remuneração indireta. O primeiro tipo refere-se ao montante total em dinheiro recebido pela pessoa, em contrapartida ao trabalho realizado. Inclui a remuneração fixa e a remuneração variável (Chiavenato, 1989). A remuneração fixa é o montante em dinheiro previamente ajustado entre a pessoa e a empresa, pago regularmente pelo trabalho realizado. Normalmente, está atrelada às tarefas e à posição ocupada pela pessoa na companhia (Chiavenato, 1989). Já a remuneração variável é o montante em dinheiro recebido em razão do alcance de determinadas metas previamente ajustadas entre a pessoa e a empresa.

A remuneração indireta é representada pelos benefícios relacionados ao trabalho realizado, concedidos às pessoas envolvidas. Seu objetivo é oferecer segurança e conforto (Chiavenato, 1989).

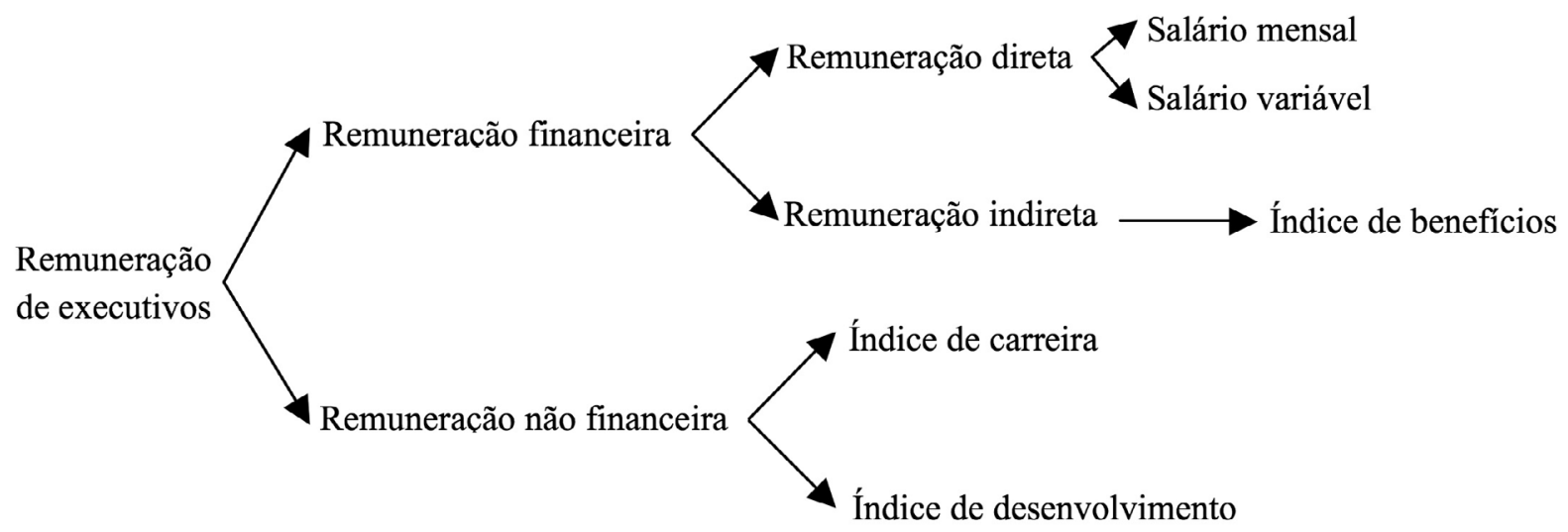

Fonte: Krauter (2009, p. 44).

Figura 1. O conceito de remuneração

As empresas, frequentemente, incorporam remuneração não financeira aos seus pacotes de remuneração dos executivos, e essa informação foi ignorada nas pesquisas realizadas (Carlon, Downs \& Wert-Gray, 2006). Aspectos relacionados à carreira e ao desenvolvimento pessoal e profissional são dois dos fatores não financeiros em questão.

Segundo o PROGEP (2012), o aspecto mais valorizado pelas pessoas é a perspectiva de crescimento profissional. Essa possibilidade é materializada por meio da carreira profissional oferecida. Em seguida, vem o treinamento e a educação, considerados aspectos fundamentais para sustentar o desenvolvimento pessoal e profissional.

Em relação à carreira, as ações das organizações englobam mecanismos de planejamento e acompanhamento de carreira, de recolocação em caso de demissão, de recrutamento interno e de preparação para a aposentadoria.

Quanto ao desenvolvimento pessoal e profissional, as empresas têm adotado um processo de aprendizagem contínuo. O objetivo é desenvolver as competências empresariais e humanas consideradas críticas para o negócio (Eboli, 2002).

O desempenho organizacional é um tema frequente em muitas áreas da Administração. Trata-se de um assunto que interessa tanto a acadêmicos quanto a executivos. Embora a importância do conceito de desempenho seja amplamente reconhecida, não existe consenso entre os pesquisadores a respeito de como operacionalizá-lo (Venkatraman \& Ramanujam, 1986). Alguns autores, como Chakravarthy (1986), Keats $(1990)$ e Venkatraman e Ramanujam $(1986,1987)$ acreditam que o conceito "desempenho" tem múltiplas dimensões. Assim, para medi-lo, é preciso utilizar mais de um indicador.

Venkatraman e Ramanujam (1987) demonstraram que o construto "desempenho financeiro" tem, pelo menos, duas dimensões distintas: crescimento e rentabilidade. Cada uma dessas dimensões pode ser operacionalizada por um ou mais indicadores. A rentabilidade, por exemplo, pode ser medida por indi- 
cadores como retorno sobre patrimônio líquido (ROE), retorno sobre ativos (ROA) e retorno sobre investimentos (ROI). O crescimento pode ser dimensionado por indicadores, como aumento das vendas.

Os trabalhos que focaram a relação entre remuneração e desempenho partiram do pressuposto de que o sistema de remuneração é um mecanismo essencial. Por meio dele, os esforços individuais são direcionados para os objetivos estratégicos do negócio. Quando o sistema de remuneração é estruturado de maneira adequada, esse processo pode contribuir para o aumento do desempenho da companhia (Gómez-Mejia \& Welbourne, 1988).

Os próximos parágrafos apresentam um breve resumo das pesquisas empíricas que estudaram a relação entre a remuneração dos executivos e o desempenho da empresa. Essas pesquisas foram realizadas em países em que as informações sobre a remuneração dos executivos estão disponíveis. No Brasil, a resistência das empresas em divulgar os dados de remuneração dificulta a realização de pesquisas sobre o tema.

A pesquisa de Attaway (2000) examinou a relação entre o desempenho da empresa e a remuneração do CEO (Chief Executive Officer) em uma amostra de 42 grandes companhias do setor de computadores e eletrônicos, nos Estados Unidos. Os dados secundários foram coletados no período de 1992 a 1996. As variáveis de controle utilizadas foram: idade do CEO, tempo no cargo, porcentagem de ações da empresa em poder do CEO e grau de escolaridade do CEO. O ROE mediu o desempenho da empresa. Os resultados das análises de correlação e de regressão mostraram que existia uma relação fraca, mas positiva, entre o desempenho da empresa e a remuneração do CEO.

Ozkan (2007) examinou a relação entre a remuneração do CEO e o desempenho da empresa, em uma amostra de 390 empresas britânicas não financeiras, presentes no índice FTSE, no período de 1999 a 2005. A remuneração incluiu: salário-base, bônus, stock options e planos de incentivo de longo prazo. O desempenho foi medido pelo retorno da ação e pelo ROA. Como variáveis de controle foram utilizadas as variáveis de governança: concentração de propriedade e estrutura do conselho. Utilizou-se também o tamanho da empresa, medido pelas vendas e pela oportunidade de crescimento. Este foi dimensionado pelo Q de Tobin. Os resultados dos testes de regressão indicaram que existe uma relação positiva e significante entre remuneração recebida em dinheiro (salário-base + bônus) e desempenho. Revelaram ainda uma relação positiva, mas não significante, entre remuneração total e desempenho.

No Brasil, Camargos, Helal e Boas (2007) analisaram a relação existente entre o desempenho financeiro e a remuneração dos executivos de 29 empresas de capital aberto com American Depositary Receipts (ADR) listadas em bolsas norte-americanas. Os dados de remuneração foram coletados do Relatório 20-F e incluíram a remuneração média recebida pelos membros do conselho de administração e da diretoria executiva, e os indicadores financeiros foram coletados da Economatica. Os dados eram do ano fiscal de 2005. Os resultados da análise de regressão múltipla apontaram uma relação positiva e significante entre a remuneração e o desempenho financeiro.

Krauter (2009) investigou a relação entre a remuneração dos executivos e o desempenho financeiro da empresa, em uma amostra de 44 empresas do setor industrial. A remuneração referente ao exercício de 2006 incluiu: salário-base, salário variável, índice de benefícios, índice de carreira e índice de desenvolvimento. O desempenho financeiro foi medido pelos indicadores contábeis: crescimento das vendas, ROE e margem líquida sobre as vendas, de dois exercícios sociais: 2006 e 2007. A análise de correlação de Pearson mostrou associações fracas e negativas entre as seguintes variáveis: a) índice de carreira e crescimento das vendas de 2006; b) índice de carreira e ROE de 2006; c) índice de desenvolvimento e ROE de 2006. A análise de correlação de Spearman apontou: a) associação fraca e positiva entre índice de benefícios e margem líquida sobre as vendas de 2006; b) associação fraca e negativa entre índice de desenvolvimento e ROE de 2006. Os resultados da análise de regressão linear múltipla não permitiram comprovar a existência de relação positiva e significante entre a remuneração dos executivos e o desempenho financeiro das empresas.

Em outro trabalho, Krauter (2012) investigou a relação entre a remuneração dos executivos e o desempenho das empresas em uma amostra de 79 empresas de diversos setores. Para operacionalizar a variável independente "remuneração" foram utilizados o salário mensal, o salário variável e três índices criados para a pesquisa: benefícios, carreira e desenvolvimento. Os dados de remuneração eram do exercício de 
2008. O desempenho financeiro foi medido pelos indicadores contábeis - crescimento das vendas, ROE e ROA do exercício de 2008. O porte e o setor foram utilizados como variáveis de controle. Os resultados da análise de regressão linear múltipla não permitiram comprovar a existência de relação positiva e significante entre a remuneração dos executivos e o desempenho financeiro das empresas.

\section{Metodologia}

A pesquisa é descritiva e utiliza o método quantitativo. A análise de regressão linear múltipla é aplicada para testar a seguinte hipótese: Existe relação positiva e significante entre a remuneração dos executivos e o desempenho financeiro nas empresas brasileiras. Essa técnica foi utilizada na maioria dos trabalhos anteriores.

Os dados utilizados na pesquisa são secundários. As informações das variáveis independentes foram extraídas do banco de dados do Programa de Estudos em Gestão de Pessoas (PROGEP), da Fundação Instituto de Administração (FIA). Os dados das variáveis dependentes foram extraídos do banco de dados da Fundação Instituto de Pesquisas Contábeis, Atuariais e Financeiras (FIPECAFI).

O PROGEP é responsável pela realização da pesquisa que elege anualmente as melhores empresas para se trabalhar no Brasil. E a FIPECAFI é responsável pela publicação das "500 Melhores e Maiores" empresas do Brasil.

O método de amostragem não probabilístico foi empregado. A amostra é formada por 82 empresas não financeiras, com informações disponíveis nos dois bancos de dados citados acima. Para tabular os dados, utilizou-se o programa estatístico Statistical Package for Social Science (SPSS) - versão 16.0 for Windows.

As informações sobre remuneração provêm do exercício de 2008 e referem-se ao pagamento recebido por diretores, vice-presidentes e presidentes, os quais são denominados, neste trabalho, de "executivos". Para operacionalizar a variável remuneração, foram coletadas as seguintes informações no banco de dados do PROGEP:

a) valor do salário mensal nominal médio em dezembro de 2008, em reais, dos executivos;

b) valor médio recebido pelos executivos durante o ano de 2008, em reais, a título de remuneração variável e/ou bônus;

c) acesso dos executivos a 12 benefícios: assistência médica, consultórios médicos nas instalações da empresa; assistência odontológica; subsídio para a compra de medicamentos; atendimento psicológico; seguro de vida em grupo; subsídio para a formação educacional; subsídio para a especialização profissional; subsídio para o estudo de idiomas; suporte à educação dos filhos; subsídio para a aquisição de moradia; financiamentos e empréstimos.

d) acesso dos executivos a 27 mecanismos de estímulo e suporte à carreira. Esses mecanismos compreendem: planejamento e acompanhamento do desenvolvimento profissional; estímulo e suporte para o planejamento de carreira; recolocação para os executivos demitidos; recrutamento interno; informações sobre as possibilidades de carreira; preparação para a aposentadoria.

e) acesso dos executivos a 8 mecanismos de estímulo à educação: programas educacionais que incorporam a identificação das competências críticas empresariais e humanas; múltiplas formas de aprendizagem; programas que reflitam o compromisso da empresa com a cidadania empresarial; gerentes e líderes envolvidos com o processo de aprendizagem; programas disseminadores da cultura organizacional; sistemas eficazes de avaliação dos investimentos em educação e dos resultados obtidos; compartilhamento de conhecimentos e troca de experiências; parcerias com instituições de ensino superior.

A partir dessas informações sobre benefícios, carreira e educação foram criados três índices: de benefícios, de carreira e de desenvolvimento, utilizando a metodologia desenvolvida por Krauter (2012). 
Para criar o índice de benefícios, que mede o acesso dos executivos aos 12 benefícios citados acima (item c), foi atribuído 1 ponto para cada benefício oferecido pela empresa a todos os seus executivos; 0 ponto para cada benefício não oferecido. Os pontos foram somados, e o resultado corresponde ao índice de benefícios da organização. A pontuação varia de 0 a 12, isto é, a empresa que não oferece nenhum dos 12 benefícios a seus executivos tem índice igual a 0; a companhia que oferece os 12 benefícios a todos os seus executivos tem índice igual a 12.

Para criar o índice de carreira, que mede o acesso dos executivos aos 27 mecanismos de estímulo e suporte à carreira citados acima (item d), foi utilizado o mesmo critério do índice anterior. Foi atribuído 1 ponto para cada mecanismo de estímulo e suporte à carreira oferecido pela empresa a todos os seus executivos; 0 ponto para cada mecanismo de estímulo e suporte à carreira não oferecido.

Os pontos foram somados, e o resultado corresponde ao índice de carreira. A pontuação do índice varia de 0 a 27. A empresa que não oferece nenhum dos 27 mecanismos de estímulo e suporte à carreira a seus executivos tem índice de carreira igual a 0. Já aquela que oferece os 27 mecanismos a todos os seus executivos tem índice igual a 27.

Para criar o índice de desenvolvimento, que mede o acesso dos executivos aos 8 mecanismos de estímulo à educação citados acima (item e), foi utilizado o mesmo procedimento dos índices anteriores. Foi atribuído 1 ponto para cada mecanismo de estímulo à educação oferecido pela empresa a todos os seus executivos; 0 ponto para cada mecanismo não oferecido.

Os pontos foram somados, e o resultado corresponde ao índice de desenvolvimento. A pontuação do índice varia de 0 a 8 . A companhia que não oferece nenhum dos 8 mecanismos de estímulo à educação a seus executivos tem índice de desenvolvimento igual a 0 . Já aquela que oferece os 8 mecanismos a todos os seus executivos tem índice igual a 8.

Para medir o desempenho financeiro das empresas, foram utilizados três indicadores contábeis crescimento das vendas, retorno sobre patrimônio líquido e retorno sobre ativos, dos exercícios sociais de 2008 e de 2009. Esses indicadores estão entre os mais utilizados em pesquisas empíricas (Carton \& Hofer, 2006; Lee, Hall \& Rutherford, 2003). Apesar de os indicadores contábeis apresentarem algumas limitações, optou-se por sua utilização em razão da presença, na amostra, de empresas de capital fechado. Essa opção também possibilita comparar os resultados deste estudo com os resultados de pesquisas realizadas em outros contextos.

O crescimento das vendas mostra a evolução da receita bruta de vendas em reais, descontada a inflação média, apontada pela variação do IGP-M. O indicador é expresso em porcentagem. O retorno sobre patrimônio líquido resulta da divisão do lucro líquido, ajustado de acordo à inflação, pelo patrimônio líquido, que é atualizado pelos efeitos da inflação. O produto é multiplicado por 100, para ser expresso em porcentagem. O retorno sobre ativos resulta da divisão do lucro líquido ajustado pela inflação, pelo ativo total ajustado para reconhecer os efeitos inflacionários. O produto é multiplicado por 100, para ser expresso em porcentagem.

As variáveis de controle foram selecionadas com base na possível influência que exercem sobre as variáveis dependentes e independentes. A literatura destaca que o porte das empresas e o setor de atuação são dois fatores relevantes. Neste trabalho, o porte foi definido como o logaritmo natural do ativo total em 2008. Foram utilizadas variáveis binárias para representar os diferentes setores. Essas variáveis atribuem valor 1 para as empresas pertencentes a um dos setores em específico e 0 para as empresas pertencentes aos demais setores.

\section{Apresentação e Análise dos Resultados}

A Tabela 1 apresenta o porte das empresas da amostra segundo o critério adotado pelo PROGEP (2012). Das 82 empresas da amostra, 48,8\% são de grande porte, $37,8 \%$ são de médio porte e $13,4 \%$ são de pequeno porte. 
Tabela 1

Porte das empresas da amostra

\begin{tabular}{llcc} 
& \multicolumn{1}{c}{ Porte das empresas } & $\mathbf{n}$ & \% \\
\hline Pequeno porte - entre 100 e 500 funcionários & 11 & 13,4 \\
\hline Médio porte - entre 501 e 1.500 funcionários & 31 & 37,8 \\
\hline Grande porte - mais de 1.500 funcionários & 40 & 48,8 \\
\hline Total & $\mathbf{8 2}$ & $\mathbf{1 0 0}$ \\
\hline
\end{tabular}

As empresas pertencem a 17 setores de atuação. Os setores com maior número de empresas são: Indústria da Construção, com 12,2\%; Serviços, com 12,2\%; Química e Petroquímica, com 11\%; e Varejo, com 11\% (Tabela 2).

Tabela 2

Setor de atuação das empresas da amostra

\begin{tabular}{|c|c|c|}
\hline Setor de atuação & $\mathbf{n}$ & $\%$ \\
\hline Química e Petroquímica & 9 & 11,0 \\
\hline Eletroeletrônico & 4 & 4,9 \\
\hline Farmacêutico & 3 & 3,7 \\
\hline Telecomunicações & 3 & 3,7 \\
\hline Papel e Celulose & 1 & 1,2 \\
\hline Mineração & 2 & 2,4 \\
\hline Indústria Digital & 1 & 1,2 \\
\hline Atacado & 1 & 1,2 \\
\hline Transporte & 2 & 2,4 \\
\hline Varejo & 9 & 11,0 \\
\hline Bens de Consumo & 5 & 6,1 \\
\hline Energia & 6 & 7,3 \\
\hline Auto indústria & 7 & 8,5 \\
\hline Indústria da Construção & 10 & 12,2 \\
\hline Siderurgia e Metalurgia & 6 & 7,3 \\
\hline Produção Agropecuária & 3 & 3,7 \\
\hline Serviços & 10 & 12,2 \\
\hline Total & 82 & 100,0 \\
\hline
\end{tabular}

As siglas das variáveis utilizadas nesta pesquisa são apresentadas na Figura 2. A Tabela 3 apresenta as medidas descritivas das variáveis de remuneração. Os valores do salário mensal médio e do salário variável médio foram transformados devido à grande variação apresentada. Duas empresas não forneceram os valores do salário mensal médio e do salário variável médio recebido por seus executivos em 2008. 


\begin{tabular}{|c|c|}
\hline Nome da variável & Sigla \\
\hline Salário Mensal Médio & salmen \\
\hline Salário Variável Médio & salvar \\
\hline Índice de Benefícios & ibenef \\
\hline Índice de Carreira & icarr \\
\hline Índice de Desenvolvimento & idesen \\
\hline Crescimento das Vendas - 2008 & cven08 \\
\hline Retorno sobre Patrimônio Líquido - 2008 & roe08 \\
\hline Retorno sobre Ativos - 2008 & roa08 \\
\hline Crescimento das Vendas - 2009 & cven09 \\
\hline Retorno sobre Patrimônio Líquido - 2009 & roe09 \\
\hline Retorno sobre Ativos - 2009 & roa09 \\
\hline Porte & porte \\
\hline Setor & setor \\
\hline
\end{tabular}

Figura 2. Sigla das variáveis da pesquisa

Catorze empresas não pagam salário variável a seus executivos, por isso, o valor mínimo igual a zero. Pesquisas apontam que o salário variável tem uma influência positiva nos direcionadores de criação de valor. Aumento da produtividade, aumento na satisfação dos funcionários, aumento na qualidade do produto ou serviço e aumento na satisfação dos clientes são alguns dos direcionadores favoravelmente influenciados com a implantação de programas de remuneração variável (Krauter, 2007). Assim, existem oportunidades a serem exploradas pelas empresas.

Tabela 3

Medidas descritivas das variáveis de remuneração

\begin{tabular}{lcccccc}
\hline & $\mathbf{n}$ & média & mediana & desvio-padrão & mínimo & máximo \\
\hline In(salmen) & 80 & 10,15 & 10,27 & 0,61 & 7,14 & 11,10 \\
\hline In(salvar) & 66 & 11,63 & 11,78 & 1,53 & 7,23 & 16,57 \\
\hline ibenef & 82 & 7,12 & 8,00 & 2,28 & 0 & 11 \\
\hline icarr & 82 & 11,32 & 11,50 & 6,56 & 0 & 26 \\
\hline idesen & 82 & 5,78 & 6,50 & 2,39 & 0 & 8 \\
\hline
\end{tabular}

O índice de benefícios mede o acesso dos executivos a 12 benefícios. Quanto maior o índice, mais bem colocada estará a empresa. Trata-se de uma proporção que considera um número mais elevado de benefícios para uma quantidade maior de executivos. Nenhuma das empresas atingiu a pontuação máxima de 12 pontos. Assim, nenhuma delas oferece todos os benefícios a todos os executivos. Duas empresas não oferecem qualquer benefício aos executivos. A maior pontuação alcançada (11 pontos) foi obtida por apenas uma empresa. $O$ índice de benefícios médio foi de 7,12 pontos, com $50 \%$ das empresas apresentando valor igual ou inferior a 8 pontos.

Os benefícios são um mecanismo importante de atração e retenção de talentos. Se bem estruturados, podem sinalizar aos profissionais que a empresa é um bom lugar para uma relação profissional de longo prazo (Hipólito \& Dutra, 2012).

O índice de carreira mede o acesso dos executivos a 27 mecanismos de estímulo e suporte à carreira. Assim como no índice anterior, quanto maior o índice, mais bem colocada estará a empresa. Nenhuma empresa atingiu a pontuação máxima de 27 pontos. A maior pontuação alcançada ( 26 pontos) foi obtida por apenas uma empresa. Seis empresas não oferecem qualquer mecanismo de estímulo e suporte à carreira dos executivos. O índice de carreira apresentou valor médio de 11,32 pontos, oscilando entre 0 e 26 . Cinquen- 
ta por cento das empresas apresentaram valor igual ou inferior a 11,50 pontos. Esses resultados apontam que as empresas estão oferecendo poucos mecanismos de estímulo e suporte à carreira de seus executivos.

Como mencionado anteriormente, a carreira oferecida pela empresa é um item muito valorizado pelos executivos (PROGEP, 2012). Segundo Ulrich et al. (1991), quando as organizações dão pouco suporte à carreira de seus profissionais, estes passam a repensar sua dedicação à organização e podem passar a não se engajar inteiramente nas ações da organização. Assim, trata-se de um contexto que sinaliza importantes oportunidades a serem exploradas pelas organizações.

O índice de desenvolvimento mede o acesso dos executivos a 8 mecanismos de estímulo à educação e ao desenvolvimento profissional. Como nos índices anteriores, quanto maior o índice, mais bem colocada estará a empresa. A pontuação máxima de 8 pontos foi atingida por 24 empresas. Seis empresas não oferecem qualquer estímulo à educação e ao desenvolvimento profissional de seus executivos.

O índice de desenvolvimento apresentou valor médio de 5,78 pontos, variando de 0 a 8 . Cinquenta por cento das empresas indicaram valor igual ou inferior a 6,50 pontos. Os programas educacionais, os treinamentos e as parcerias com instituições de ensino permitem o desenvolvimento efetivo pessoal e profissional dos executivos, munindo-os dos conhecimentos e das habilidades apropriadas para desempenhar suas funções na organização (Fombrun, Tichy \& Devanna, 1984).

Apesar de as empresas da amostra serem consideradas benchmarking em gestão de pessoas, esses resultados apontam que elas estão oferecendo poucos mecanismos de estímulo e suporte à carreira e ao desenvolvimento profissional e pessoal de seus executivos. Sugere-se que as empresas avaliem essas questões. Existem oportunidades a serem exploradas para atrair e reter os melhores talentos.

A Tabela 4 apresenta as medidas descritivas dos indicadores contábeis. Algumas empresas não disponibilizaram todos os indicadores financeiros. O crescimento das vendas de 2008 apresentou valor médio de $16,06 \%$, variando de $-79,05 \%$ a $169,81 \%$. O ROE de 2008 apresentou valor médio de $22,46 \%$, oscilando entre $-134,17 \%$ e $377,28 \%$. O ROA de 2008 indicou valor médio de $9,89 \%$, variando de -13,59\% a 167,23\%.

O valor médio do crescimento das vendas de 2009 foi de 0,35\%, ficando entre -55,31\% e 175,61\%. O valor médio do ROE de 2009 foi de $21,06 \%$, variando de $-15,02 \%$ a 94,68\%. O ROA de 2009 apresentou valor médio de $8,51 \%$, oscilando entre $-5,06 \%$ e $31,56 \%$.

Tabela 4

Medidas descritivas das variáveis de desempenho financeiro

\begin{tabular}{lcccccc} 
& $\mathbf{n}$ & média & mediana & desvio-padrão & mínimo & máximo \\
\hline cven08(\%) & 77 & 16,06 & 5,92 & 35,34 & $-79,05$ & 169,81 \\
\hline roe08 (\%) & 82 & 22,46 & 17,70 & 49,51 & $-134,17$ & 377,28 \\
\hline roa08 (\%) & 82 & 9,89 & 6,30 & 19,67 & $-13,59$ & 167,23 \\
\hline cven09 (\%) & 79 & 0,35 & $-3,28$ & 26,56 & $-55,31$ & 175,61 \\
\hline roe09 (\%) & 78 & 21,06 & 19,11 & 17,11 & $-15,02$ & 94,68 \\
\hline roa09 (\%) & 78 & 8,51 & 7,37 & 7,18 & $-5,06$ & 31,56 \\
\hline
\end{tabular}

O coeficiente de correlação de Spearman foi utilizado para verificar se existia associação linear entre as variáveis de remuneração e as variáveis de desempenho financeiro. A Tabela 5 mostra os coeficientes de correlação das variáveis da pesquisa.

A variável $\ln ($ salmen) está significativamente correlacionada a $5 \%$ com a variável roe 09 . O coeficiente é positivo e fraco $(\rho=0,239)$. O coeficiente de correlação entre $\ln ($ salmen) e roa09 é significante a $5 \%$, positivo e fraco $(\rho=0,259)$. 
Existe uma associação positiva, fraca e significante a $5 \%$ entre $\ln ($ salvar) e roa09 $(\rho=0,308)$.

A variável ibenef está significativamente correlacionada a $1 \%$ com cven 09 . O coeficiente é negativo e fraco $(\rho=0,294)$. Esperava-se que a relação fosse positiva, que a oferta de benefícios por parte da empresa teria uma influência positiva no comportamento dos executivos.

Não há associação linear entre as demais variáveis de remuneração e as variáveis de desempenho financeiro. Assim, a análise de correlação de Spearman apontou a existência de relação positiva e significante entre: salário mensal médio (logaritmo) e ROE de 2009, salário mensal médio (logaritmo) e ROA de 2009, salário variável médio (logaritmo) e ROA de 2009. E relação negativa e significante entre índice de benefícios e crescimento das vendas de 2009.

Voltando-se à Figura 1 do início do artigo, o teste de correlação apontou que existe relação entre remuneração financeira e desempenho financeiro. A relação é positiva e significante entre remuneração direta e desempenho financeiro; e negativa entre remuneração indireta e desempenho financeiro. Não foram encontradas relações entre remuneração não financeira e desempenho financeiro.

É interessante notar que existe uma defasagem de tempo entre os investimentos em pessoas e a geração de resultados. Os investimentos feitos em 2008 geraram resultados no exercício seguinte - 2009.

Tabela 5

Matriz de correlação de Spearman

\begin{tabular}{|c|c|c|c|c|c|c|c|c|c|c|c|}
\hline & In(salmen) & In(salvar) & ibenef & icarr & idesen & cven08 & roe08 & roa08 & cven09 & roe09 & roa09 \\
\hline \multirow[b]{2}{*}{ In(salmen) } & 1 & & & & & & & & & & \\
\hline & 80 & & & & & & & & & & \\
\hline \multirow{3}{*}{ In(salvar) } & $0,472 * *$ & 1 & & & & & & & & & \\
\hline & 0,000 & & & & & & & & & & \\
\hline & & & & & & & & & & & \\
\hline \multirow{3}{*}{ ibenef } & 0,231 * & 0,074 & 1 & & & & & & & & \\
\hline & 0,039 & 0,556 & & & & & & & & & \\
\hline & 80 & 66 & 82 & & & & & & & & \\
\hline \multirow{3}{*}{ icarr } & $0,243 *$ & 0,150 & $0,501 * *$ & 1 & & & & & & & \\
\hline & 0,030 & 0,228 & 0,000 & & & & & & & & \\
\hline & 80 & 66 & 82 & 82 & & & & & & & \\
\hline \multirow{3}{*}{ idesen } & 0,158 & $0,269 *$ & $0,287 * *$ & 0,466 ** & 1 & & & & & & \\
\hline & 0,162 & 0,029 & 0,009 & 0,000 & & & & & & & \\
\hline & 80 & 66 & 82 & 82 & 82 & & & & & & \\
\hline \multirow{3}{*}{ cven 08} & $-0,046$ & $-0,024$ & $-0,067$ & $-0,064$ & $-0,022$ & 1 & & & & & \\
\hline & 0,692 & 0,851 & 0,560 & 0,579 & 0,850 & & & & & & \\
\hline & 75 & 62 & 77 & 77 & 77 & 77 & & & & & \\
\hline \multirow{3}{*}{ roe08 } & $-0,089$ & 0,033 & $-0,012$ & $-0,006$ & $-0,030$ & 0,159 & 1 & & & & \\
\hline & 0,433 & 0,791 & 0,913 & 0,960 & 0,789 & 9,169 & & & & & \\
\hline & 80 & 66 & 82 & 82 & 82 & 77 & 82 & & & & \\
\hline \multirow{3}{*}{ roa08 } & 0,010 & 0,111 & 0,073 & 0,085 & $-0,020$ & 0,097 & 0,856 ** & 1 & & & \\
\hline & 0,932 & 0,374 & 0,513 & 0,449 & 0,862 & 0,401 & 0,000 & & & & \\
\hline & 80 & 66 & 82 & 82 & 82 & 77 & 82 & 82 & & & \\
\hline \multirow{3}{*}{ cven09 } & 0,105 & 0,045 & $-0,294 * \star$ & $-0,093$ & 0,035 & 0,131 & $-0,154$ & $-0,235^{\star}$ & 1 & & \\
\hline & 0,365 & 0,729 & 0,008 & 0,414 & 0,763 & 0,263 & 0,175 & 0,037 & & & \\
\hline & 77 & 63 & 79 & 79 & 79 & 75 & 79 & 79 & 79 & & \\
\hline \multirow{3}{*}{ roe09 } & $0,239 *$ & 0,173 & 0,032 & 0,141 & 0,114 & 0,150 & $0,311 * *$ & 0,212 & $0,266^{*}$ & 1 & \\
\hline & 0,039 & 0,178 & 0,781 & 0,217 & 0,319 & 0,203 & 0,006 & 0,063 & 0,018 & & \\
\hline & 76 & 62 & 78 & 78 & 78 & 74 & 78 & 78 & 78 & 78 & \\
\hline \multirow{3}{*}{ roa09 } & $0,259 *$ & $0,308^{*}$ & 0,102 & 0,143 & 0,124 & 0,083 & $0,473 * *$ & $0,560 * *$ & 0,077 & $0,780 * \star$ & 1 \\
\hline & 0,024 & 0,015 & 0,376 & 0,212 & 0,279 & 0,484 & 0,000 & 0,000 & 0,502 & 0,000 & \\
\hline & 76 & 62 & 78 & 78 & 78 & 74 & 78 & 78 & 78 & 78 & 78 \\
\hline
\end{tabular}

** $\mathrm{e}$ * correspondem à significância estatística nos níveis de $1 \%$ e 5\%, respectivamente. Obs.: A primeira linha apresenta o coeficiente de correlação de Spearman; a segunda, o p-valor do teste de significância bilateral; a terceira apresenta o número de observações. 
Para testar a hipótese de que existe relação positiva e significante entre a remuneração dos executivos e o desempenho financeiro das empresas, utilizou-se a análise de regressão linear múltipla. Foram desenvolvidas regressões múltiplas, utilizando, simultaneamente, todas as variáveis de remuneração como variável independente e as variáveis de desempenho financeiro, alternadamente, como dependentes. $\mathrm{O}$ porte e o setor foram utilizados como variáveis de controle. Foram testados seis modelos. O modelo geral empregado foi:

$$
\mathrm{DF}_{\mathrm{i}}=\beta_{0}+\beta_{1} \ln (\text { salmen })_{\mathrm{i}}+\beta_{2} \ln \left(\text { salvar }_{\mathrm{i}}+\beta_{3} \text { ibenef }_{\mathrm{i}}+\beta_{4} \mathrm{icarr}_{\mathrm{i}}+\beta_{5} \text { idesen }_{\mathrm{i}}+\beta_{6} \text { porte }_{\mathrm{i}}+\sum_{j=1}^{17} \delta j \text { setor }_{\mathrm{ji}}+\mu_{\mathrm{i}}\right.
$$

Onde: $i$ representa a $i$-ésima empresa; DF representa as variáveis de desempenho financeiro; $\delta_{j}$ representa o coeficiente relativo as variáveis binárias de setor de atuação; $\mu$ é o termo de erro.

A Tabela 6 apresenta os resultados das regressões múltiplas estimadas com o método dos mínimos quadrados, utilizando o logaritmo natural do ativo total como proxy para porte.

Dos seis modelos testados, apenas um apresentou significância estatística, ao nível de $1 \%$, o que utilizou roa09 (Coluna 6) como variável dependente. Esse modelo apresenta um R-quadrado ajustado de $41,1 \%$. A análise da significância dos parâmetros aponta que o coeficiente da variável $\ln$ (salmen) é negativo e significante a $10 \%$; o da variável $\ln$ (salvar) é positivo e significante a $1 \%$; o da variável ibenef é positivo e significante a $5 \%$; o do porte é negativo e significante a $1 \%$; e o da constante é positivo e significante a $5 \%$.

A análise dos coeficientes do modelo com cven08 (Coluna 1) mostra que os das variáveis $\ln$ (salmen) e porte são negativos e significantes a $10 \%$; o da constante é positivo e significante a $1 \%$.

No modelo com roe08 (Coluna 2), os coeficientes de ibenef e de idesen são negativos e significantes a $10 \%$; o de icarr é positivo e significante a $5 \%$; o de porte é negativo e significante a $1 \%$; e o da constante é positivo e significante a $10 \%$.

Já no modelo com roa08 (Coluna 3), os coeficientes das variáveis icarr, idesen e porte são significativos a $5 \%$, sendo que o de icarr apresenta sinal positivo e os de idesen e porte, sinal negativo.

Os modelos com cven09 (Coluna 4) e roe09 (Coluna 5) como variáveis dependentes não apresentaram coeficientes significativos.

Os resultados apresentam evidências de que existe relação significante entre a remuneração dos executivos e o desempenho financeiro das empresas. Voltando-se à Figura 1 do início do artigo, os resultados apontam que existe relação entre remuneração financeira e desempenho financeiro e entre remuneração não financeira e desempenho financeiro.

Os modelos testados atendem a todos os pressupostos da análise de regressão múltipla. 
Tabela 6

Resultados dos modelos de regressão linear múltipla

\begin{tabular}{|c|c|c|c|c|c|c|}
\hline Variáveis & $\begin{array}{c}\text { cven08 } \\
\text { (1) }\end{array}$ & $\begin{array}{l}\text { roe08 } \\
\text { (2) }\end{array}$ & $\begin{array}{l}\text { roa08 } \\
\text { (3) }\end{array}$ & $\begin{array}{c}\text { cven09 } \\
\text { (4) }\end{array}$ & $\begin{array}{l}\text { roe09 } \\
\text { (5) }\end{array}$ & $\begin{array}{c}\text { roa09 } \\
\text { (6) }\end{array}$ \\
\hline In(salmen) & $\begin{array}{l}-19,234 \\
(-1,706) \#\end{array}$ & $\begin{array}{l}-6,314 \\
(-0,364)\end{array}$ & $\begin{array}{l}-1,702 \\
(-0,245)\end{array}$ & $\begin{array}{l}9,521 \\
(0,984)\end{array}$ & $\begin{array}{l}-4,641 \\
(-0,716)\end{array}$ & $\begin{array}{l}-3,223 \\
(-1,713) \#\end{array}$ \\
\hline In(salvar) & $\begin{array}{l}1,359 \\
(0,362)\end{array}$ & $\begin{array}{l}4,523 \\
(0,796)\end{array}$ & $\begin{array}{l}2,286 \\
(1,004)\end{array}$ & $\begin{array}{l}4,193 \\
(1,309)\end{array}$ & $\begin{array}{l}0,927 \\
(0,444)\end{array}$ & $\begin{array}{l}2,367 \\
(3,908)^{\star *}\end{array}$ \\
\hline ibenef & $\begin{array}{l}-1,338 \\
(-0,465)\end{array}$ & $\begin{array}{l}-7,338 \\
(-1,749) \#\end{array}$ & $\begin{array}{l}-2,601 \\
(-1,547)\end{array}$ & $\begin{array}{l}-0,591 \\
(-0,257)\end{array}$ & $\begin{array}{l}2,253 \\
(-1,500)\end{array}$ & $\begin{array}{l}1,109 \\
(3,544)^{*}\end{array}$ \\
\hline icarr & $\begin{array}{l}0,499 \\
(0,386)\end{array}$ & $\begin{array}{l}4,263 \\
(2,175)^{\star}\end{array}$ & $\begin{array}{l}1,973 \\
(2,512)^{*}\end{array}$ & $\begin{array}{l}-1,659 \\
(-1,501)\end{array}$ & $\begin{array}{l}0,765 \\
(1,038)\end{array}$ & $\begin{array}{l}-0,006 \\
(-0,028)\end{array}$ \\
\hline idesen & $\begin{array}{l}-1,177 \\
(-0,420)\end{array}$ & $\begin{array}{l}-7,563 \\
(-1,817) \#\end{array}$ & $\begin{array}{l}-4,145 \\
(-2,485)^{\star}\end{array}$ & $\begin{array}{l}1,318 \\
(0,555)\end{array}$ & $\begin{array}{l}0,364 \\
(0,234)\end{array}$ & $\begin{array}{l}0,094 \\
(0,207)\end{array}$ \\
\hline porte & $\begin{array}{l}-7,006 \\
(-1,727) \#\end{array}$ & $\begin{array}{l}-16,523 \\
(-2,876)^{\star \star}\end{array}$ & $\begin{array}{l}-5,157 \\
(-2,240)^{\star}\end{array}$ & $\begin{array}{l}-1,587 \\
(-0,456)\end{array}$ & $\begin{array}{l}-2,083 \\
(-0,917)\end{array}$ & $\begin{array}{l}-2,433 \\
(-3,691)^{\star \star}\end{array}$ \\
\hline setor & incluído & incluído & incluído & incluído & incluído & incluído \\
\hline constante & $\begin{array}{l}320,908 \\
(2,845)^{\star *}\end{array}$ & $\begin{array}{l}296,917 \\
(1,724) \#\end{array}$ & $\begin{array}{l}89,854 \\
(1,302)\end{array}$ & $\begin{array}{l}-92,456 \\
(-0,974)\end{array}$ & $\begin{array}{l}67,447 \\
(1,059)\end{array}$ & $\begin{array}{l}42,370 \\
(2,291)^{*}\end{array}$ \\
\hline $\mathbf{R}^{2}$ ajustado & 0,135 & 0,074 & 0,067 & 0,032 & $-0,048$ & 0,411 \\
\hline Sig. F & 0,165 & 0,279 & 0,295 & 0,391 & 0,625 & 0,002 \\
\hline $\mathbf{n}$ & 60 & 63 & 63 & 60 & 59 & 59 \\
\hline
\end{tabular}

As variáveis binárias para o setor de atuação foram incluídas nas regressões. Elas foram omitidas da tabela por limitação de espaço. Os números em parênteses indicam a estatística $t$.

**, * e \# correspondem à significância estatística nos níveis de 1\%,5\% e 10\%, respectivamente.

A Figura 3 apresenta um resumo dos resultados. Os resultados do teste de correlação de Spearman e de regressão linear múltipla apontam que existe relação entre salário mensal médio e retorno sobre patrimônio líquido do exercício de 2009 e entre salário mensal médio e retorno sobre ativos do exercício de 2009. A relação é positiva e significante a $5 \%$ no teste de correlação e negativa e significante a $10 \%$ na regressão. Já a relação entre salário variável médio e retorno sobre ativos do exercício de 2009 é positiva tanto no teste de correlação como na regressão. Assim, os resultados apontam a existência de relação entre remuneração direta e desempenho financeiro. Apontam, também, que os investimentos em pessoas podem demandar um prazo para apresentar resultados. Os investimentos feitos no exercício de 2008 geraram resultados no exercício de 2009.

Os resultados encontrados no presente trabalho diferem dos resultados das pesquisas que utilizaram os mesmos constructos para operacionalizar a variável remuneração. Essas pesquisas desenvolvidas por Krauter $(2009,2012)$ não encontraram relação significante entre remuneração dos executivos e desempenho financeiro das empresas. 


\begin{tabular}{lcc}
\hline \multicolumn{1}{c}{ Relações entre variáveis } & Correlação de Spearman & Regressão múltipla \\
\hline Salário mensal médio e crescimento das vendas de 2008 & & $(-)$ \# \\
\hline Salário mensal médio e ROE de 2009 & $(+)^{*}$ & $(-) \#$ \\
\hline Salário mensal médio e ROA de 2009 & $(+)^{*}$ & $(-) \#$ \\
\hline Salário variável médio e ROA de 2009 & $(+)^{*}$ & $(+)^{* *}$ \\
\hline Índice de benefícios e crescimento das vendas de 2009 & $(-)^{* *}$ & $(+)^{*}$ \\
\hline Índice de benefícios e ROA de 2009 & & $(+)^{*}$ \\
\hline Índice de carreira e ROE de 2008 & $(+)^{*}$ \\
\hline Índice de carreira e ROA de 2008 & $(-) \#$ \\
\hline Índice de desenvolvimento e ROE de 2008 & $(-)^{*}$ \\
\hline Índice de desenvolvimento e ROA de 2008 & & \\
\hline
\end{tabular}

Figura 3. Resumo dos resultados dos testes

**, * e \# correspondem à significância estatística nos níveis de 1\%,5\% e 10\%, respectivamente.

(+) indica relação positiva entre as variáveis; (-) indica relação negativa entre as variáveis.

Obs.: os testes utilizaram o logaritmo natural das variáveis salmen e salvar.

\section{Considerações Finais}

De acordo com a teoria de agência, o pacote de remuneração é considerado um dos mecanismos mais eficientes para induzir o executivo, maximizador da própria utilidade e avesso ao risco, a agir com a finalidade de aumentar o desempenho da empresa. O objetivo desta pesquisa foi investigar a relação entre a remuneração dos executivos e o desempenho financeiro nas empresas brasileiras. Ela se diferencia das pesquisas anteriores, realizadas em outros contextos, ao adotar conceitos mais amplos para operacionalizar as variáveis. Enquanto as anteriores utilizaram o salário fixo e o salário variável para operacionalizar a variável remuneração, esta utiliza, além dos salários, três índices criados para a pesquisa: benefícios, carreira e desenvolvimento. Além disso, as anteriores utilizaram apenas um indicador contábil. Essa pesquisa utilizou três indicadores contábeis de dois exercícios sociais.

A análise descritiva dos salários indicou que algumas empresas não pagam salário variável a seus executivos. Pesquisas realizadas apontam que planos de remuneração variável têm uma influência favorável no desempenho da empresa, desde que desenvolvidos de maneira apropriada, ou seja, atrelando o pagamento ao alcance de metas. Já a análise descritiva dos índices mostrou que as empresas estão oferecendo pouco estímulo e suporte para o crescimento profissional de seus executivos. Pesquisas demonstram que a possibilidade de crescimento profissional é um dos principais fatores para atrair e reter talentos. Assim, existem oportunidades a serem exploradas pelas empresas.

A análise de correlação de Spearman apontou a existência de associação significante entre remuneração financeira e desempenho financeiro. Os resultados da análise de regressão linear múltipla mostraram que existe relação entre remuneração financeira e desempenho financeiro e entre remuneração não financeira e desempenho financeiro. Esses resultados apontam que a remuneração pode ajudar a direcionar os esforços dos executivos em direção aos objetivos estratégicos do negócio, contribuindo para que a empresa alcance níveis superiores de desempenho financeiro.

As principais contribuições deste trabalho estão em: ampliar o conhecimento existente sobre a relação entre a remuneração dos executivos e o desempenho financeiro das empresas no Brasil, já que as pesquisas sobre o tema ainda são escassas, devido à falta de divulgação dos dados de remuneração; abrir perspectivas para a realização de novas pesquisas, utilizando essa abordagem mais ampla com dados de outros exercícios sociais; fornecer subsídios para as empresas aperfeiçoarem seus sistemas de remuneração, aumentando sua capacidade de atrair, reter, desenvolver e mobilizar seus executivos em torno de seus objetivos. Assim, o trabalho apontou aspectos que devem ser observados pelas empresas ao estruturar os pacotes de remuneração de seus executivos: a inclusão de remuneração variável, de benefícios, de mecanismos de estímulo à carreira e à educação. 
A pesquisa apresenta algumas limitações. O método de amostragem empregado para selecionar as empresas da amostra é não probabilístico. Assim, não é possível generalizar os resultados encontrados para a população. O tamanho da amostra também é uma limitação. Devido à dificuldade para se obter, no Brasil, os dados contábeis e os dados de remuneração, a amostra é composta por 82 empresas. $\mathrm{O}$ fato de as empresas de capital fechado - categoria predominante no universo empresarial brasileiro - não serem obrigadas a divulgar suas demonstrações financeiras, dificulta a realização de trabalhos que necessitem desses dados. A utilização de informações contábeis também pode ser um limitador, pois é passível de distorções.

Com a edição da Instrução n. ${ }^{\circ}$ 480/09 da Comissão de Valores Mobiliários (CVM), que instituiu novas regras para a divulgação da remuneração dos administradores pelas companhias abertas, dados adicionais sobre a remuneração dos executivos estarão disponíveis para os pesquisadores e poderão ser adotados para operacionalizar a variável em futuros estudos.

\section{Referências}

Attaway, M. C. (2000). A study of the relationship between company performance and CEO compensation. American Business Review, 18(1), 75-85.

Bálkin, D. B. \& Gómez-Mejia, L. R. (1987). Toward a contingency theory of compensation strategy. Strategic Management Journal, 8(2), 169-182.

Barkema, H. G. \& Gómez-Mejia, L. R. (1998). Managerial compensation and firm performance: a general research framework. Academy of Management Journal, 41(2), 135-145.

Camargos, M. A.; Helal, D. H. \& Boas, A. P. (2007, outubro). Análise empírica da relação entre a remuneração de executivos e o desempenho financeiro de empresas brasileiras. Anais do Encontro Nacional de Engenharia de Produção, Foz do Iguaçu, PR, Brasil, 27.

Carlon, D. M.; Downs, A. A. \& Wert-Gray, S. (2006). Statistics as fetishes: the case of financial performance and executive compensation. Organizational Research Methods, 9(4), 475-490.

Carton, R. B. \& Hofer, C. W. (2006). Measuring organizational performance: metrics for entrepreneurship and strategic management research. Northampton: Edward Elgar.

Chakravarthy, B. S. (1986). Measuring strategic performance. Strategic Management Journal, 7(5), 437-458.

Chiavenato, I. (1989). Recursos humanos na empresa. São Paulo: Atlas.

Eboli, M. (2002). O desenvolvimento das pessoas e a educação corporativa. In: Fleury, M. T. L. et al. As pessoas na organização. São Paulo: Editora Gente.

Fombrun, C. J.; Tichy, N. M. \& Devanna, M. A. (1984). Strategic human resource management. New York: Wiley.

Gómez-Mejia, L. R. \& Welbourne, T. M. (1988). Compensation strategy: an overview and future steps. HR Human Resource Planning, 11(3), 173-189.

Hipólito, J. A. M. \& Dutra, J. S. (2012). Remuneração e recompensas. Rio de Janeiro: Elsevier.

Jensen, M. C. \& Meckling, W. H. (1976). Theory of the firm: managerial behavior, agency costs, and ownership structure. Journal of Financial Economics, 3(4), 305-360.

Kato, T.; Kim, W. \& Lee, Ju-Ho. (2005). Executive compensation, firm performance and Chaebols in Korea: evidence from new panel data. SSRN. Recuperado em 24 agosto, 2013, de http://ssrn.com/abstract $=548921$.

Keats, B. W. (1990). Diversification and business economic performance revisited: issues of measurement and causality. Journal of Management, 16(1), 61-72. 
Krauter, E. (2007). Participação nos lucros e resultados: influência nos direcionadores de valor. São Paulo: Saint Paul.

Krauter, E. (2009). Contribuições do sistema de remuneração dos executivos para o desempenho financeiro: um estudo com empresas industriais brasileiras. Tese de doutorado, Universidade de São Paulo, São Paulo, SP, Brasil. Recuperado em 12 dezembro, 2012 de http://www.teses.usp.br/teses/disponiveis/12/12139/tde-29052009-092957.

Krauter, E. (2012). Executive compensation and financial performance in Brazilian companies. SSRN. Recuperado em 12 dezembro, 2012, de http://ssrn.com/abstract=217104.

Larrate, M. (2013). Governança corporativa e remuneração dos gestores. São Paulo: Atlas.

Lee, J.; Hall, E. H., Jr. \& Rutherforf, M. W. (2003). A comparative study of U.S. and Korean firms: changes in diversification and performance. International Journal of Commerce \& Management, 13(1), 11-41.

Oskan, N. (2007). CEO compensation and firm performance: an empirical investigation of UK panel data. SSRN. Recuperado em 2 dezembro, 2010, de http://ssrn.com/abstract $=1102703$.

PROGEP. (2012). Laudo técnico 2012. Recuperado em 5 setembro, 2012 de http://www.progep.org.br/ MelhoresEmpresas/default.aspx.

Ulrich, D.; Halbrook, R.; Meder, D.; Stuchlik, M. \& Thorpe, S. (1991). Employee and customer attachment: synergies for competitive advantage. Human Resource Planning, 14(2), 89-102.

Venkatraman, N. \& Ramanujam, V. (1986). Measurement of business performance in strategy research: a comparison of approaches. Academy of Management Review, 11(4), 801-814.

Venkatraman, N. \& Ramanujam, V. (1987). Measurement of business economic performance: an examination of method convergence. Journal of Management, 1(1),109-122. 